\title{
Thermodynamics of Hydrochloric Acid in 80 Weight Percent 2-Methoxyethanol and 20 Weight Percent Water From 10 to $50{ }^{\circ} \mathrm{C}$
}

\author{
Harry P. Thun*, Bert R. Staples, and Roger G. Bates**
}

Institute for Materials Research, National Bureau of Standards, Washington, D.C. 20234

(June 4, 1970)

\begin{abstract}
Electromotive-force measurements of cells of the type $\mathrm{Pt}, \mathrm{H}_{2} \mid \mathrm{HCl}(m)$ in 2-methoxyethanol $+\mathrm{H}_{2} \mathrm{O} \mid \mathrm{AgCl}, \mathrm{Ag}$ at nine temperatures ranging from 10 to $50{ }^{\circ} \mathrm{C}$ were used to derive (a) the standard emf of the cell in 80 weight percent 2-methoxyethanol (methylcellosolve), (b) the activity coefficient of $\mathrm{HCl}$, (c) the relative partial molal enthalpy and heat capacity of $\mathrm{HCl}$, and (d) the thermodynamic constants for the transfer of $\mathrm{HCl}$ from water to 80 weight percent methylcellosolve. The molality of the acid ranged from 0.006 to $0.106 \mathrm{~mol} \mathrm{~kg}^{-1}$. To obtain the standard emf it was necessary to correct for ion-pair formation and to use the extended terms of the Debye-Hückel theory. The standard emf varied with temperature $\left(t,{ }^{\circ} \mathrm{C}\right)$ according to the equation $E_{t}^{\circ}=0.14382-1.517 \times 10^{-3} t-3.8317 \times 10^{-6} t^{2}$ $-2.3838 \times 10^{-9} t^{3}$. Vapor pressures and dielectric constants for this mixture were measured over the temperature range. At $25{ }^{\circ} \mathrm{C}$ the solvent has a vapor pressure of $2506.5 \mathrm{Nm}^{-2}(18.8 \mathrm{~mm} \mathrm{Hg})$ and a dielectric constant of 31.5 .
\end{abstract}

Key words: Activity coefficients; non-aqueous emf; standard emf; thermodynamic constants for $\mathrm{HCl}$ transfer.

\section{Introduction}

As a possible solvent for the determination of stability constants of metal ion complexes, 2-methoxyethanol (methylcellosolve) can be considered as very promising. It not only dissolves numerous organic compounds but also many inorganic salts such as several of the metal perchlorates including sodium perchlorate and the lanthanide perchlorates. Unfortunately, the pure solvent has a rather low dielectric constant (about 2.3 at $25^{\circ} \mathrm{C}$ ), and it therefore seemed preferable to examine a suitable mixture with water.

Simon et al. $[1,2]^{1}$ have already carried out an impressive number of $p K$ determinations for organic acids and bases in a mixture containing $80 \mathrm{wt} \%$ 2 -methoxyethanol and 20 wt $\%$ water. A $p H$ cell with glass electrode and calomel electrode was used. The $\mathrm{pH}$ scale in this medium has not been standardized, and consequently the measurements of Simon and his coworkers were based on the aqueous standard buffer solutions. In order to obtain unambiguous results in future electromotive-force studies on complex stabilities and $p K$ values in $80 \mathrm{wt} \%$ methylcellosolve, it is necessary to establish a $p H$ scale in this medium. The present study on the thermodynamics of $\mathrm{HCl}$ was

\footnotetext{
*On leave 1968-69 from Laboratory for Analytical Chemistry, J. Plateaustraat, 22, Gent, Belgium, 9000

**Present address: Dept. of Chemistry, University of Florida, Gainesville, Florida 32601.

${ }^{1}$ Figures in brackets indicate the literature references at the end of this paper.
}

carried out as a first step toward the establishment of a standard acidity scale in a solvent containing $80 \mathrm{wt} \%$ 2 -methoxyethanol and 20 wt $\%$ water.

Measurements of the emf of the cell

$\mathrm{Pt} ; \mathrm{H}_{2}(\mathrm{~g}), \mathrm{HCl}(m)$ in $80 \mathrm{wt} \%$

2-methoxyethanol, AgCl; Ag

were made from 10 to $50{ }^{\circ} \mathrm{C}$ at intervals of $5{ }^{\circ} \mathrm{C}$ and for six molalities of hydrochloric acid in the nominal range of 0.006 to $0.1 \mathrm{~mol} \mathrm{~kg}^{-1}$. In order to correct the observed emf to the standard 1 atm partial pressure of hydrogen, it was necessary to measure the vapor pressure of the mixed solvent. The evaluation of the standard emf of the cell at each temperature further necessitated measurements of the dielectric constant $\epsilon$ and the density $\rho_{0}$ of the solvent. The procedure followed for the analysis of the emf data was very similar to the one adopted by Pool and Bates [3].

\section{Experimental Procedure}

The 2-methoxyethanol was obtained commercially, and gas chromatographic analysis showed the water content to be less than 0.03 percent. No other volatile impurities could be detected, and no further purification was attempted. The mixed solvent was prepared by weighing distilled water and the 2 -methoxyethanol. 
The dielectric constant of the mixed solvent was measured at 10,25 , and $50{ }^{\circ} \mathrm{C}$, using freshly distilled water and spectro-grade acetone as reference materials. The Multi-Dekameter instrument ${ }^{2}$ was used for these measurements. The temperature of the cell was adjusted to within $0.1{ }^{\circ} \mathrm{C}$ of the nominal temperature of circulating water from a constant-temperature bath. The results are given in table 1 .

TABLE 1. Dielectric constants of the 80 wt \% 2methoxyethanol solvent

\begin{tabular}{|c|c|}
\hline \hline$t$ & $\epsilon$ \\
\hline$\left({ }^{\circ} \mathrm{C}\right)$ & \\
10 & 34.7 \\
25 & 31.5 \\
50 & 27.8 \\
\hline
\end{tabular}

For the vapor pressure measurements, a flask containing the solvent was immersed in a water bath, the temperature of which was controlled to $\pm 0.01{ }^{\circ} \mathrm{C}$. The flask was connected to a U-tube mercury manometer and the pumping system, which included a mercury diffusion pump. Because 2-methoxyethanol attacks the high-vacuum grease, Teflon stopcocks had to be used.

Before the flask was connected to the vacuum line, the temperature of the solvent was lowered to $-72{ }^{\circ} \mathrm{C}$ in an ethanol-solid carbon dioxide mixture, so that the evacuation of the system would not cause any change in the composition of the liquid. To avoid condensation of vapors in the manometer, the latter was placed in a controlled air bath with a transparent plastic panel. In this way, the manometer could be kept at $56^{\circ} \mathrm{C}$ throughout the measurements. The rest of the apparatus, except for the flask, was wrapped with heating tape and kept at a temperature well above $50{ }^{\circ} \mathrm{C}$. Before starting the measurements, the pressure in the apparatus was reduced below $1 \mu \mathrm{m} \mathrm{Hg}$. The readings were taken with a cathetometer giving a precision of $0.05 \mathrm{~mm} \mathrm{Hg}$.

The measured values for the vapor pressure of the 80 wt percent 2-methoxyethanol solvent under study in the temperature range 10 to $50^{\circ} \mathrm{C}$ are given in table 2 . They were fitted to the following equation

TABLE 2. Vapor pressures of the 80 wt \% 2-methoxyethanol solvent

\begin{tabular}{c|c|c|c}
\hline \hline$t$ & \multicolumn{2}{|c|}{ Pressure } & $\sigma$ \\
\hline${ }^{\circ} \mathrm{C}$ & $\mathrm{Nm}^{-2}$ & $\mathrm{~mm} \mathrm{Hg}$ & $\mathrm{mm} \mathrm{Hg}$ \\
10 & 973.3 & $(7.3)$ & $(0.1)$ \\
15 & 1346.6 & $(10.1)$ & $(0.2)$ \\
20 & 1813.2 & $(13.6)$ & $(0.2)$ \\
25 & 2506.5 & $(18.8)$ & $(0.3)$ \\
30 & 3373.1 & $(25.3)$ & $(0.2)$ \\
35 & 4479.6 & $(33.6)$ & $(0.1)$ \\
40 & 5919.5 & $(44.4)$ & $(0.2)$ \\
45 & 7732.7 & $(58.0)$ & $(0.4)$ \\
50 & 10052. & $(75.4)$ & $(0.6)$ \\
\hline
\end{tabular}

${ }^{2}$ Multi-Dekameter, Type MDK-06, Wiss. Techn. Werkstätten, Weilheim, Obb., Germany. Reference to trade name is made only for identification and does not imply in any way Reference to trade name is made only for identification and does
the endorsement of the product by the National Bureau of Standards.

$$
\log p=9.061-\frac{2321.7}{T}
$$

by the method of least squares. In this equation, $T$ is the thermodynamic temperature $t\left({ }^{\circ} \mathrm{C}\right)+273.15$.

The densities of the mixed solvent were measured with a pycnometer. The results are presented in table 3 .

TABLE 3. Density of the $80 w t \%$ 2-methoxyethanol

\begin{tabular}{c|r}
\multicolumn{2}{c}{ solvent } \\
\hline \hline$t$ & Density \\
\hline${ }^{\circ} \mathrm{C}$ & $\mathrm{g} \mathrm{cm}-3$ \\
10 & 0.9997 \\
15 & .9955 \\
20 & .9910 \\
25 & .9868 \\
30 & .9824 \\
35 & .9781 \\
40 & .9739 \\
45 & .9693 \\
50 & .9647 \\
\hline
\end{tabular}

High-purity hydrochloric acid was used to make a stock solution, of molality approximately $0.1 \mathrm{~mol} \mathrm{~kg}^{-1}$, in the mixed solvent. The hydrochloric acid was tested for the presence of bromide and found to be satisfactory $(<0.002$ mole percent). Solutions of six different molalities $m$ were prepared by weighing the stock solution and diluting it with a weighed amount of the mixed solvent.

The design of the cells, preparation of electrodes, purification of the hydrogen gas, and other experimental details have been described previously [4, 5].

The values of the emf were corrected to $1 \mathrm{~atm}$ partial pressure of hydrogen and are given in table 4. Each entry in the table represents the average of three replicate cells prepared for each molality of hydrochloric acid. Each cell was measured at all nine temperatures. The lowest and highest emf values for replicate cells differed, at most, by $0.1 \mathrm{mV}$. The emf at $25{ }^{\circ} \mathrm{C}$ was recorded three times, namely, at the beginning, middle, and end of the run. The three values usually agreed within $0.05 \mathrm{mV}$.

\section{Standard Emf of the Cell}

The standard emf $\left(E^{\circ}\right)$ of the cell used is derived from the measured emf $(E)$ by the Nernst equation:

$$
E^{\circ}=E+(2 R T / F) \ln \left(m \gamma_{ \pm}\right)=E+(2 R T / F) \ln \left(m^{\prime} \gamma_{ \pm}^{\prime}\right)
$$

where $m$ and $\gamma_{ \pm}$are the stoichiometric molality and mean molal activity coefficient of $\mathrm{HCl}$ in the solvent under study, and $m^{\prime}$ and $\gamma_{ \pm}^{\prime}$ are the actual molality of ionized $\mathrm{HCl}$ and the true mean activity coefficient. In a first attempt to derive $E^{\circ}, \gamma_{ \pm}$was calculated by a form of the Debye-Hückel equation

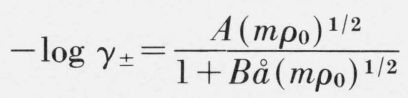


TABLE 4. Emf (in volts) of the cell $\mathrm{Pt} ; \mathrm{H}_{2}(g, 1$ atm), $\mathrm{HCl}(\mathrm{m})$ in 80 wt \% 2-methoxyethanol, $\mathrm{AgCl} ; \mathrm{Ag}$

\begin{tabular}{c|c|c|c|c|c|r|r|r|r}
\hline \multirow{2}{*}{$m$} & \multicolumn{7}{c}{ Temperature, ${ }^{\circ} \mathrm{C}$} \\
\cline { 2 - 9 } & 10 & 15 & 20 & 25 & 30 & 35 & 40 & 45 & 50 \\
\hline$m o l ~ \mathrm{gg}^{-1}$ & & & & & & & & & \\
0.006012 & 0.39176 & 0.38873 & 0.38550 & 0.38212 & 0.37840 & 0.37471 & 0.37086 & 0.36674 & 0.36240 \\
.010897 & .36671 & .36333 & .35976 & .35614 & .35221 & .34823 & .34425 & .33991 & .33557 \\
.02183 & .33804 & .33432 & .33045 & .32650 & .32231 & .31807 & .31365 & .30897 & .30448 \\
.04213 & .31188 & .30768 & .30353 & .29928 & .29486 & .29028 & .28564 & .28073 & .27575 \\
.07855 & .28714 & .28283 & .27834 & .27370 & .26888 & .26408 & .25921 & .25411 & .24902 \\
.10620 & .27509 & .27063 & .26596 & .26131 & .25647 & .25150 & .24641 & .24111 & .23591 \\
\hline
\end{tabular}

where $\rho_{0}$ is the solvent density, $\stackrel{a}{a}$ is the ion-size parameter, and the Debye-Hückel constants $A$ and $B$ took into account the temperature and dielectric constant of the solvent. From these $\gamma_{ \pm}$values, the apparent $E^{\circ}$ was calculated according to

$$
E^{\circ \prime}=E^{\circ}+\beta m=E+(2 R T / F) \ln \left(m \gamma_{ \pm}\right) .
$$

Least squares treatment of $E^{\circ}$ as a function of $m$ permitted extrapolation to zero ionic strength and yielded preliminary values for $E^{\circ}$. However, straight lines could not be obtained, suggesting that the hydrochloric acid was not completely ionized in the medium under investigation. There were no results available for the ion-pair dissociation constant $K_{d}$ for $\mathrm{HCl}$ in this medium, so an empirical treatment had to be used, as was the case in earlier work in 95 percent ethanol [3].

The following procedure was used. The mean activity coefficient $\gamma_{+}$was derived from eq (3) and values of $m^{\prime}$ were calculated for each stoichiometric molality $(m)$ by the equation

$$
K_{d}=\frac{\left(m^{\prime} \gamma_{ \pm}\right)^{2}}{\left(m-m^{\prime}\right)}
$$

A reasonable value of $K_{d}$ in the range 0.01 to 1.0 was chosen. With these estimates of $m^{\prime}$, the true molality of dissociated $\mathrm{HCl}$, new values for the $\gamma_{+}^{\prime}$ "true" activity coefficient were calculated by an extended form of eq (3):

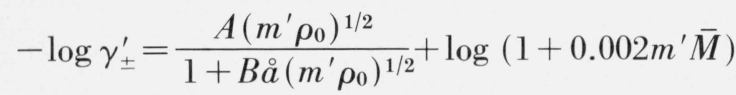

where $\bar{M}$ is the mean molar mass of the mixed solvent $\left(46.273 \mathrm{~g} \mathrm{~mol}^{-1}\right)$. The $\gamma_{ \pm}^{\prime}$ so obtained was substituted in a modified form of eq (5)

$$
K_{d}=\frac{\left(m^{\prime} \gamma_{ \pm}^{\prime}\right)^{1 / 2}}{\left(m-m^{\prime}\right)}
$$

and used to obtain a new $m^{\prime}$. This iterative procedure was repeated $n$ times, until the difference

$$
\left|\gamma_{ \pm n}^{\prime}-\gamma_{ \pm-1}^{\prime}\right| ₹ 10^{-5}
$$

From these values of $\gamma_{ \pm}$and $m^{\prime}, E^{\circ}$ was calculated by the method of least squares from $E^{\circ \prime}$ defined by

$$
E^{\circ \prime}=E^{\circ}+\beta m^{\prime}=E+(2 R T / F) \ln \left(m^{\prime} \gamma_{ \pm}^{\prime}\right) .
$$

For each value of $K_{d}$ chosen, a set of $\stackrel{a}{a}$ values was used to calculate $m^{\prime}, \gamma_{ \pm}^{\prime}$, and $E^{\circ \prime}$. Decreasing ranges of both $K_{d}$ and $\stackrel{a}{a}$ were selected until values were found that produced the minimum standard deviation of $E^{\circ}$ values from a linear function of $m^{\prime}$. These were taken to be the true values of $K_{d}$ and $\stackrel{\circ}{a}$. The resulting intercept $\left(E^{\circ}\right)$ of the plot of $E^{\circ \prime}$ as a function of $m^{\prime}$ seemed to vary only a few hundredths of a millivolt with changes in $K_{d}$ of 0.005 and changes in $\stackrel{\circ}{a}$ of $0.05 \AA$. The final $E^{\circ}$ at each temperature is given together with the "best" values of $K_{d}$ and $\stackrel{a}{a}$. Ion-pairing seems to be less extensive in $80 \mathrm{wt} \%$ methylcellosolve $\left(K_{d}=0.204\right)$ than in 95 percent ethanol $\left(K_{d}=0.033\right.$ [3] $)$. This conclusion is consistent with the slightly higher dielectric constant and the considerably larger amount of water in the methylcellosolve-water solvent. The standard emf can be represented by the equation

$$
\begin{aligned}
E_{t}^{\circ}=0.14382-0.001517 t-3.8317 \times 10^{-6} t^{2} \\
-2.3838 \times 10^{-9} t^{3}
\end{aligned}
$$

where $t$ is the temperature in ${ }^{\circ} \mathrm{C}$. Values of $E^{\circ}$ calculated by eq (9) are also compared with the experimental values in table 5 .

TABLE 5. Summary of results for the standard emf $\left(\mathrm{E}^{\circ}\right)$ of the cell in 80 wt \% 2-methoxyethanol solvent

\begin{tabular}{c|c|c|c|c|c|c}
\hline \hline$t$ & $K_{d}$ & $(a)$ & $E^{\circ}$ & ${ }^{\mathrm{a}} \sigma_{d}$ & $\begin{array}{c}E^{\circ} \\
\mathrm{calc}{ }^{\mathrm{b}}\end{array}$ & $\Delta E^{\circ}$ \\
\hline${ }^{\circ} C$ & & & $V$ & $m V$ & & $m V$ \\
10 & 0.366 & 4.59 & 0.12822 & 0.04 & 0.12827 & 0.05 \\
15 & .306 & 4.79 & .12027 & .04 & .12019 & .08 \\
20 & .227 & 4.73 & .11192 & .03 & .11193 & .01 \\
25 & .204 & 4.60 & .10353 & .04 & .10344 & .09 \\
30 & .130 & 4.60 & .09466 & .08 & .09479 & .13 \\
35 & .116 & 4.37 & .08589 & .08 & .08592 & .03 \\
40 & .089 & 4.36 & .07693 & .10 & .07685 & .08 \\
45 & .071 & 4.41 & .06763 & .10 & .06757 & .05 \\
50 & .058 & 4.21 & .05804 & .17 & .05808 & .04 \\
\hline
\end{tabular}

a Standard deviation of $E^{\circ}$.

${ }^{\mathrm{b}}$ By eq (9). 
TABLE 6. Stoichiometric mean activity coefficient $\left(\gamma_{ \pm}\right)$of hydrochloric acid in 80 wt \% 2-methoxyethanol from 10 to $50^{\circ} \mathrm{C}$

\begin{tabular}{c|c|c|c|c|c|c}
\hline \multirow{2}{*}{$t$} & & \multicolumn{4}{|c|}{$m(\mathrm{HCl}), \mathrm{mol} \mathrm{kg}^{-1}$} & \\
\cline { 2 - 6 } & 0.006012 & 0.010897 & 0.02183 & 0.04213 & 0.07855 & 0.10620 \\
\hline${ }^{\circ} C$ & & & & & & \\
10 & 0.751 & 0.692 & 0.621 & 0.551 & 0.490 & 0.464 \\
15 & .747 & .687 & .615 & .545 & .482 & .456 \\
20 & .740 & .679 & .606 & .535 & .472 & .446 \\
25 & .735 & .672 & .598 & .526 & .464 & .437 \\
30 & .728 & .663 & .587 & .514 & .454 & .425 \\
35 & .723 & .656 & .578 & .506 & .444 & .416 \\
40 & .717 & .648 & .570 & .496 & .434 & .407 \\
45 & .711 & .640 & .561 & .487 & .424 & .398 \\
50 & .704 & .629 & .548 & .476 & .413 & .386 \\
\hline
\end{tabular}

\section{Thermodynamic Properties of Hydrochloric Acid}

With the aid of eq (2) and the stoichiometric molalities, the stoichiometric activity coefficients $\gamma_{ \pm}$were derived from $E^{\circ}$ and the measured values of $E$. These values are shown in table 6 . For each molality, $\log \gamma_{ \pm}$ was fitted to a power series of the form

$$
-\log \gamma_{ \pm}=A+B T+C T^{2}
$$

where $T$ is the thermodynamic temperature, $t\left({ }^{\circ} \mathrm{C}\right)$ +273.15 .

The constants of this equation are given in table 7 , together with the standard deviations of the calculated values of $\log \gamma_{ \pm}$.

TABLE 7. Constants of the eqation $-\log \gamma_{ \pm}=\mathrm{A}+\mathrm{BT}+\mathrm{CT}^{2}$

\begin{tabular}{c|c|c|c|c}
\hline \hline$m$ & $A$ & $B \times 10^{3}$ & $C \times 10^{6}$ & $\sigma \times 10^{3}$ \\
\hline$m o l \mathrm{~kg}^{-1}$ & & & & \\
0.006012 & 0.195708 & -1.0828 & 2.9359 & 0.5 \\
.010897 & .518064 & -3.2864 & 7.1346 & .4 \\
.02183 & .41377 & -2.5559 & 6.4359 & .9 \\
.04213 & .409875 & -2.4130 & 6.6281 & 1.0 \\
.07855 & .675343 & -4.0528 & 9.7507 & 0.5 \\
.10620 & .402071 & -2.2042 & 6.9208 & .8 \\
\hline
\end{tabular}

The relative partial molal enthalpy $\bar{L}_{2}$ and the relative partial molal heat capacity $\bar{J}_{2}$ of hydrochloric acid in the medium studied were calculated from the constants $B$ and $C$ of eq (10) by the following formulas:

and

$$
\bar{L}_{2}=\left(2 R T^{2} \ln 10\right)(B+2 C T)
$$

$$
\bar{J}_{2}=(4 R T \ln 10)(B+3 C T) \text {. }
$$

The values obtained for $\bar{L}_{2}$ at 10,25 , and $50{ }^{\circ} \mathrm{C}$ and for $\bar{J}_{2}$ at $25^{\circ} \mathrm{C}$ are summarized in table 8 .

The standard thermodynamic quantities for the transfer process
TABLE 8. Relative partial molal enthalpy $\left(\overline{\mathrm{L}}_{2}\right)$ and

\begin{tabular}{|c|c|c|c|c|c|c|}
\hline \multirow{2}{*}{$t$} & \multicolumn{6}{|c|}{$m$ (HCl), mol kg-1 } \\
\hline & 0.006012 & 0.010897 & 0.02183 & 0.04213 & 0.07855 & 0.1062 \\
\hline \multicolumn{7}{|c|}{$\bar{L}_{2}, \mathrm{~J} \mathrm{~mol}^{-1}$} \\
\hline $\begin{array}{l}10 \\
25 \\
50\end{array}$ & $\begin{array}{l}1780 \\
2273 \\
3257\end{array}$ & $\begin{array}{l}2315 \\
3295 \\
5297\end{array}$ & $\begin{array}{l}3342 \\
4363 \\
6412\end{array}$ & $\begin{array}{l}4115 \\
5239 \\
7480\end{array}$ & $\begin{array}{l}4509 \\
5995 \\
8992\end{array}$ & $\begin{array}{l}5121 \\
6519 \\
9307\end{array}$ \\
\hline \multicolumn{7}{|c|}{$\bar{J}_{2}, \mathrm{~J} \mathrm{~K}^{-1} \mathrm{~mol}^{-1}$} \\
\hline 25 & 35 & 71 & 73 & 80 & 107 & 100 \\
\hline
\end{tabular}
relative partial molal heat capacity $\left(\mathrm{J}_{2}\right)$ of hydrochloric acid in $80 \mathrm{wt} \%$ 2-methoxyethanol

$\mathrm{HCl}\left(\right.$ in $\left.\mathrm{H}_{2} \mathrm{O}\right)=\mathrm{HCl}$ (in 80 wt $\%$

2-methoxyethanol-20 wt \% water)

can be derived from the standard emf $\left(E^{\circ}\right)$ of the cell in water [6] and in $80 \mathrm{wt} \% 2$-methoxyethanol together with the variation of $E^{\circ}$ with temperature. From eq (9) the standard Gibbs energy of transfer $\left(\Delta G_{t}^{\circ}\right)$ is found to be

$\Delta G_{t}^{\circ}=-31338.1+254.465 T-0.607549 T^{2}$

and

$$
+7.90581 \times 10^{-4} T^{3}
$$

$\Delta S_{t}^{\circ}=+254.465-1.21510 T+2.37174 \times 10^{-3} T^{2}$

while

$$
\Delta H_{t}^{\circ}=\Delta G_{t}+T \Delta S_{t}^{\circ} .
$$

For $25{ }^{\circ} \mathrm{C}$ the thermodynamic functions for the transfer of $\mathrm{HCl}$ have the following values:

$$
\begin{aligned}
& \Delta G_{t}^{\circ}=11477.0 \mathrm{~J} \mathrm{~mol}^{-1} \\
& \Delta S_{t}^{\circ}=-103.0 \mathrm{JK}^{-1} \mathrm{~mol}^{-1} \\
& \Delta H_{t}^{\circ}=-19237.0 \mathrm{~J} \mathrm{~mol}^{-1}
\end{aligned}
$$


The large positive value for the transfer free energy suggests that the affinity of 2-methoxyethanol for $\mathrm{HCl}$ is less than that of water, or, in other words, that water is the more basic component of the solvent mixture. In view of the structural changes characteristic of alcohol-water mixtures [7], however, judgments of this sort must be made with caution.

\section{References}

[1] Simon, W., Meuche, D., and Heilbronner, E., Helv. Chim. Acta 39, 290 (1956).
[2] Simon, W., Mörikofer, A., and Heilbronner, E., Helv. Chim. Acta 40, 1918 (1957).

[3] Pool, K. H., and Bates, R. G., J. Chem. Thermodynamics 1, 21 (1969).

[4] Bates, R. G., Determination of $p H$, Ch. 9 and Appendix (John Wiley \& Sons, New York, N.Y., 1964).

[5] Gary, R., Bates, R. G., and Robinson, R. A., J. Phys. Chem. 68, 1186 (1964).

[6] Bates, R. G., and Bower, V. E., J. Res. Nat. Bur. Stand. (U.S.) 53, 283 (1954).

[7] Franks, F., and Ives, D. J., Quart. Rev. 20, 1 (1966).

(Paper 74A5-627) 